\title{
Effects of rice properties and emulsifiers on the quality of rice pasta
}

\author{
Hsi-Mei Lai* \\ Department of Agricultural Chemistry, National Taiwan University, Taipei, Taiwan
}

\begin{abstract}
Two commercial rice flours (GTIndica and GTJaponica, with amylose contents of 306.8 and $185.2 \mathrm{~g} \mathrm{~kg}^{-1}$ respectively) and their blended flours were used to make rice pasta. The effects of two emulsifiers (distilled glyceryl monostearate (GMS) and a commercial emulsifier (KM3000)) on the pasting and thermal properties of dried rice pasta were investigated using a Rapid Visco Analyser (RVA) and a differential scanning calorimeter (DSC). The rice pasta made from high-amylose rice flour had better extrusion properties, better texture, whiter colour, less cooking loss and better eating quality than that made from low-amylose rice flour. The maximum amount of low-amylose rice flour that could be blended in for making an acceptable quality of rice pasta was $500 \mathrm{~g} \mathrm{~kg}^{-1}$. A soft texture, low adhesiveness and low gumminess of cooked rice pasta were obtained by adding $10 \mathrm{~g} \mathrm{~kg}^{-1} \mathrm{GMS}$ SEM investigations showed that use of an emulsifier restricted the swelling of starch granules, especially for the pasta made from high-amylose rice flour.

(C) 2001 Society of Chemical Industry
\end{abstract}

Keywords: rice pasta; amylose content; emulsifier; pasting properties; texture

\section{INTRODUCTION}

Pasta is made in different shapes from a basic mixture of wheat endosperm (durum wheat semolina or wheat flour) and water, and then cooked (as fresh pasta) or dried for consumption later on. ${ }^{1,2}$ It is a popular food in western countries, and the total world pasta production is increasing year by year. Some people with a specific genetic disposition suffer from coeliac disease (or non-tropical sprue) upon consumption of food containing wheat, rye or barley. ${ }^{3,4}$ This disease is associated with the loss of villous structure of the intestinal mucous epithelial cells, which exhibit degenerative changes and have seriously impaired nutrient absorption functions. ${ }^{3,5}$ The prolamin fractions of wheat, barley and rye can be the cause of the onset of symptoms. ${ }^{6,7}$ Therefore the use of rice rather than wheat to make pasta-like products would be advantageous to people with non-tropical sprue and other allergy problems related to wheat gluten.

Rice noodle products are an important part of the diet in many oriental countries. When rice is used as the only material to make noodle-like products, it requires some starch gelatinisation to act as a binder, since rice protein lacks the functionality of wheat gluten in making a cohesive dough structure. The effects of the degree of gelatinisation (DG) of rice flour on the properties of rice noodles have been studied by many researchers using the enzymatic method. ${ }^{8-10}$ However, different DG (20-80\%) were preferred by different researchers, which suggests that the effects of
DG on the quality of rice noodles are dependent on the rice variety and processing conditions. Sometimes the extruded noodles are subjected to surface gelatinisation in boiling water or steam to improve their stability and texture. ${ }^{11}$ This process is not used by noodle manufactures in western countries. The extruded pastas are not usually surface-gelatinised before drying. ${ }^{9,12}$ Although rice noodles are usually prepared from high-amylose $\left(>250 \mathrm{~g} \mathrm{~kg}^{-1}\right)$ rice which gives a whiter colour than intermediate-amylose (200-250g $\mathrm{kg}^{-1}$ ) rice in China, dark-coloured rice noodles prepared from boiled intermediate-amylose rice (IR 48) are preferred by Filipinos. ${ }^{11,13}$ Juliano and Pascual ${ }^{14}$ also reported that satisfactory pasta products have been prepared from Italian and Russian rice with low $\left(120-200 \mathrm{~g} \mathrm{~kg}^{-1}\right)$ to intermediate amylose content.

For continuous pasta production a raw material is required which lends itself to easy processing on the presses and in the dryers. A satisfactory rice pasta product is usually smooth, mechanically strong and of uniform colour. It should maintain its shape without falling apart or splitting when cooked in boiling water, and cooked pasta should have a firm consistency without any slimy or sticky surface film. It should also be relatively free from starch while cooking in water and should be resistant to disintegration due to overcooking. Although many additives have been used to improve the processing and/or quality of rice products, emulsifiers are one of the most commonly used compounds. The fatty nature of emulsifiers enables them

\footnotetext{
* Correspondence to: Hsi-Mei Lai, Department of Agricultural Chemistry, National Taiwan University, Taipei, Taiwan 


\begin{tabular}{|c|c|c|c|c|c|c|}
\hline & \\
\hline & Rice flour & $\begin{array}{l}\text { Moisture } \\
\left(g k g^{-1}\right)\end{array}$ & $\begin{array}{c}\text { Protein } \\
\left(g \mathrm{~kg}^{-1}, \mathrm{db}\right)\end{array}$ & $\begin{array}{c}\text { Ash } \\
\left(g k g^{-1}, d b\right)\end{array}$ & $\begin{array}{c}\text { Fat } \\
\left(g \mathrm{~kg}^{-1}, d b\right)\end{array}$ & $\begin{array}{c}\text { Apparent amylose } \\
\left(g \mathrm{~kg}^{-1}, \mathrm{db}\right)\end{array}$ \\
\hline & GTIndica & $124.7 \pm 0.2$ & $69.3 \pm 0.5$ & $3.6 \pm 0.1$ & $2.2 \pm 0.1$ & $306.8 \pm 0.6$ \\
\hline able 1. Chemical composition & GTJaponica & $140.0 \pm 0.3$ & $74.8 \pm 0.4$ & $5.3 \pm 0.2$ & $2.4 \pm 0.1$ & $185.2 \pm 0.4$ \\
\hline
\end{tabular}

to act as a lubricant in the extrusion process, resulting in less nozzle wear and tear and thus making production easier. Some emulsifiers also provide a firmer consistency, a less sticky surface and better starch retention properties during cooking. The effects of emulsifiers on the pasting properties and texture of starch gel and cereal foods have been widely studied. ${ }^{15-18}$ However, few investigations have been reported on the use of emulsifiers in rice pasta processing and their effects on the quality of rice pasta.

Slight modifications to the processes of conventional pasta manufacturing facilities have been shown to be a potential means of making rice pasta for people who consume rice regularly as well as for people with allergy problems related to wheat gluten. In this study, modified processing procedures for making rice pasta were used which involved two steps of gelatinisation: pregelatinisation of rice flour before extrusion, and surface gelatinisation of rice pasta after extrusion. The objective of this study was to investigate the effects of rice flour properties as well as types and concentrations of emulsifiers on rice pasta.

\section{MATERIALS AND METHODS \\ Materials}

Two kinds of rice flour, GTIndica (from Taichung Native 1) and GTJaponica (from Tainung 67), provided by a local rice flour milling factory $(\mathrm{Gu}$ Tong
Foods Industrial Co, Ltd, Chia-Yi, Taiwan) were used in this study. The proximate composition of the rice flours was analysed according to AACC methods 4415A, 46-12, 08-01 and 30-20 for the determination of moisture, crude protein, ash and crude fat content respectively. ${ }^{19}$ The results are summarised in Table 1. The apparent amylose contents of the rice flours determined by the method of Juliano et $a l^{20}$ are also shown in Table 1 . The hydration, pasting and thermal properties of the rice flours were measured according to the methods described below and summarised in Table 2. Two emulsifiers, GMS (DIMODAN PM from Grindsted Co, Denmark) and KM3000 (Sun-An Co, Taiwan), were used in this study. The specifications of these emulsifiers showed that DIMODAN PM was $990 \mathrm{~g} \mathrm{~kg}^{-1}$ distilled glyceryl monostearate (GMS), and $\mathrm{KM} 3000$ was a mixture of $550 \mathrm{~g} \mathrm{~kg}^{-1} \mathrm{D}$-sorbitol, $300 \mathrm{~g} \mathrm{~kg}^{-1}$ soybean oil, $50 \mathrm{~g} \mathrm{~kg}^{-1}$ lecithin, $50 \mathrm{~g} \mathrm{~kg}^{-1}$ propylene glycol, $40 \mathrm{~g} \mathrm{~kg}^{-1}$ glycerin fatty acid ester and $10 \mathrm{~g} \mathrm{~kg}^{-1}$ sucrose fatty acid ester.

\section{Methods}

Rice pasta making

The rice flour was tempered to a moisture content of $40 \%$ (on a wet basis) with water or water/emulsifier mixture $\left(5,10\right.$ or $20 \mathrm{~g} \mathrm{~kg}^{-1}$ on a dry basis) overnight. The tempered rice flour was sifted using a 10-mesh screen, then arranged into a thin layer (about $1 \mathrm{~cm}$
Table 2. Hydration, pasting and thermal properties of rice flours

\begin{tabular}{|c|c|c|c|c|c|c|}
\hline \multirow[b]{2}{*}{ Rice flour } & \multicolumn{3}{|c|}{ Hydration properties ${ }^{a}$} & & & \\
\hline & WAI & $S P$ & WS (\%) & & & \\
\hline GTIndica & 2.05 & 2.06 & 1.42 & & & \\
\hline \multirow[t]{2}{*}{ GTJaponica } & 2.58 & 2.64 & 2.50 & & & \\
\hline & \multicolumn{5}{|c|}{ Pasting properties (RVA) ${ }^{\mathrm{b}}$} & \\
\hline Rice flour & PT $\left({ }^{\circ} \mathrm{C}\right)$ & $P V(R V U)$ & $B D V(R V U)$ & $\operatorname{TSBV}(R V U)$ & $F V(R V U)$ & \\
\hline GTIndica & 79.1 & 616 & 306 & 322 & 632 & \\
\hline \multirow[t]{3}{*}{ GTJaponica } & 74.1 & 520 & 190 & 244 & 474 & \\
\hline & \multicolumn{6}{|c|}{ Thermal properties $(D S C)^{\mathrm{C}}$} \\
\hline & \multicolumn{3}{|c|}{ 1st peak } & \multicolumn{3}{|c|}{ 2nd peak } \\
\hline Rice flour & $T_{10}\left({ }^{\circ} \mathrm{C}\right)$ & $T_{1 \mathrm{p}}\left({ }^{\circ} \mathrm{C}\right)$ & $\Delta H_{1}\left(J g^{-1}, d b\right)$ & $T_{20}\left({ }^{\circ} \mathrm{C}\right)$ & $T_{2 p}\left({ }^{\circ} \mathrm{C}\right)$ & $\Delta H_{2}\left(J g^{-1}, d b\right)$ \\
\hline GTIndica & 67.3 & 74.1 & 8.13 & 90.2 & 98.0 & 1.32 \\
\hline GTJaponica & 61.9 & 70.1 & 7.35 & 88.9 & 99.2 & 0.81 \\
\hline
\end{tabular}

a WAI, water absorption index; SP, swelling power; WS, water solubility.

${ }^{b} \mathrm{PT}$, pasting temperature; PV, peak viscosity; BDV, breakdown viscosity; TSBV, total setback viscosity; FV, final viscosity.

${ }^{\mathrm{c}} T_{\mathrm{o}}$, onset temperature; $T_{\mathrm{p}}$, peak temperature. 
thick) on a rack and steamed at $85^{\circ} \mathrm{C}$ for $10 \mathrm{~min}$. The steamed rice flour was extruded into rice pasta using an automatic pasta producing machine (Model D45, La Parmigiana spa, Italy) with a die of multiple openings ( $2 \mathrm{~mm}$ in diameter). The extruded rice pasta (15 cm in length) was divided into two portions, one of which was directly dried and the other further steamed at $100^{\circ} \mathrm{C}$ for $1 \mathrm{~h}$ and then dried. The extruded rice pasta was first dried at $50^{\circ} \mathrm{C}$ for $1 \mathrm{~h}$ and then at $35^{\circ} \mathrm{C}$ for $6 \mathrm{~h}$ using a laboratory dryer (Essiccatoio Statico Static Dryer, La Parmigiana spa, Italy). For the investigations related to pasting and thermal properties and the colour of rice pasta, the dried rice pasta was ground in a Udy Cyclone Mill with a $0.5 \mathrm{~mm}$ screen (Udy Corp, USA).

\section{Properties of rice pasta}

Pasting properties. The pasting properties of rice flour and dried rice pasta were determined using a Rapid Visco Analyser (RVA) Model 3-D (Newport Scientific Pty Ltd, Warriewood, Australia). A $138 \mathrm{~g} \mathrm{~kg}^{-1}$ rice flour suspension was prepared by adding $4 \mathrm{~g}$ (dry basis) of rice flour to an aluminium canister which contained $25 \mathrm{~g}$ of distilled water. A programmed heating and cooling cycle was used at a constant stirring rate $(160 \mathrm{rpm})$, where the sample was equilibrated at $35^{\circ} \mathrm{C}$ for $2 \mathrm{~min}$, heated to $95^{\circ} \mathrm{C}$ at a rate of $12^{\circ} \mathrm{C} \mathrm{min}{ }^{-1}$, held at $95^{\circ} \mathrm{C}$ for $2.5 \mathrm{~min}$ and then cooled to $35^{\circ} \mathrm{C}$ at a rate of $12^{\circ} \mathrm{C} \mathrm{min}{ }^{-1}$. These tests were done in duplicate. A plot of paste viscosity in arbitrary RVA units (RVU) versus time was used to determine the peak viscosity (PV), temperature at PV (PT), final viscosity (FV), breakdown viscosity (BDV $=\mathrm{PV}-$ trough) and total setback viscosity (TSBV $=\mathrm{FV}$-trough). The first point at which the viscosity increased at the rate of $1 \mathrm{RVUs}^{-1}$ or faster was considered as the onset temperature of gelatinisation $\left(T_{\mathrm{o}}\right)$ of rice flour.

Thermal properties. The thermal characteristics of rice flour and dried rice pasta were studied using a Thermal Analyst DSC 2910 (TA Instruments, USA), which was calibrated with indium before the analysis with an empty pan as reference. A sample of 5-5.5 mg (dry basis) was loaded into an aluminium sample pan. Water was added with a microsyringe to the sample pan to make the water content $700 \mathrm{~g} \mathrm{~kg}^{-1}$. The sample pan was then sealed, reweighed and allowed to stand for $1 \mathrm{~h}$ at room temperature. Samples were heated from 10 to $150^{\circ} \mathrm{C}$ at a rate of $5^{\circ} \mathrm{C} \mathrm{min}^{-1}$. The thermal characteristics of each sample were determined in triplicate. From the DSC curve the onset temperature $\left(T_{\mathrm{o}}\right)$, peak temperature $\left(T_{\mathrm{p}}\right)$ and transition enthalpy $(\Delta H)$ were evaluated using the TA Instruments analysis software program.

Cooking properties. Cooking tests of rice pasta, including determination of weight gain and cooking loss, were performed in triplicate by the following methods. Samples of rice pasta $(10 \mathrm{~g})$ were cooked for $10 \mathrm{~min}$ in $200 \mathrm{ml}$ of boiling water. The pasta was then drained, cooled in water, drained again and weighed immediately. The cooking water was retained and boiled to evaporate most of the water, then dried in an oven at $105^{\circ} \mathrm{C}$ until the weight was constant. The weight gain and cooking loss of pasta were calculated by the following equations:

weight gain $(\%)=$

$[($ weight of cooked rice pasta -10$) / 10] \times 100$

cooking loss $(\%)=$

(weight of dried residue in cooking water $/ 10) \times 100$

Texture. Cooked rice pasta samples prepared as described above for the cooking test were used for texture measurements. For each rice pasta sample, three positions were tested in each rice pasta string, and a total of five strings were examined. The measurements were completed within $15 \mathrm{~min}$ after cooking. Texture profile analysis (TPA) of cooked rice pasta was performed using a TA-XT2 Texture Analyser (Stable Micro System, UK) with a stainless steel spherical probe (P/0.25S, $2.5 \mathrm{~mm}$ in diameter). The test speed was $2.0 \mathrm{~mm} \mathrm{~s}^{-1}$ and the pressing depth was $25 \%$ of the sample height. Statistical analysis of the data in Table 6 was performed by two-way ANOVA using the Statistica 92 software program (StatSoft, Inc, Tulsa, OK, USA). Differences among means within the same rice flour blending groups were tested using Duncan's new multiple-range test $(p<0.05)$.

Colour. The colour of dried rice pasta was determined using a colorimeter (DRLANGE, Micro Color, Germany). The colour of each sample was assessed in duplicate.

Microstructure. The microstructure of the surface of dried rice pasta was investigated using a scanning electron microscope (JSM-6300, Jeol Co, Japan) at $20 \mathrm{kV}$ accelerating voltage. A piece of dried rice pasta $5 \mathrm{~mm}$ in length was mounted on stainless steel specimen stubs. The mounted sample was then sputtercoated with $\mathrm{Au} / \mathrm{Pd}$ for $3 \mathrm{~min}$ at $10 \mathrm{~mA}$ using an ion sputter (Ion Sputtering Device JFC-1100E, Jeol Co, Japan).

\section{RESULTS AND DISCUSSION}

\section{Partial gelatinisation of rice flour before extrusion}

The processing characteristics of partial gelatinisation of GTIndica and GTJaponica rice flours before extrusion, including water absorption (300, 350, $400,450 \mathrm{~g} \mathrm{~kg}^{-1}$ ) and hydrothermal treatment (75, $\left.85,95^{\circ} \mathrm{C} / 10,15,30,45 \mathrm{~min}\right)$, were determined in previous experiments. ${ }^{21}$ The results showed that water absorption and hydrothermal treatment had significant effects on the processing and cooking quality of rice pasta. When the rice flour was tempered at low water absorption and hydrothermally treated with a 
low degree of gelatinisation (ie short-time steaming at low temperature), the rice dough was not viscous and could be extruded into rice pasta with good shape. However, if the rice flour was tempered at high water absorption and hydrothermally treated with a high degree of gelatinisation (ie long duration of steaming at high temperature), the rice dough was too viscous to be extruded. In this study the critical processing conditions of water absorption and hydrothermal treatment of rice flour were $400 \mathrm{~g} \mathrm{~kg}^{-1}$ and steaming at $85^{\circ} \mathrm{C}$ for $10 \mathrm{~min}$ before extrusion respectively.

\section{Effects of rice properties on pasting properties}

The pasting properties of rice pasta made from GTIndica and GTJaponica rice flours and their blends (only GTIndica/GTJaponica 1:1 data shown in Fig 1) were determined using an RVA and are shown in Fig 1. All the pasting curves of dried rice pasta were similar, but the viscosity of the pasta made from $100 \%$ GTIndica rice flour was slightly higher than that of the pastas made from blended flours or $100 \%$ GTJaponica rice flour. The onset temperature of gelatinisation $\left(T_{\mathrm{o}}\right)$ and the temperature at peak viscosity (PT) of dried rice flour were significantly delayed compared to those of both raw rice flours. The viscosities of breakdown
(BDV) and total setback (TSBV) were also significantly decreased compared with raw rice flours. The correlation coefficients between the amount of GTIndica in blends and PV were 0.91 and 0.75 for rice pasta without steaming after extrusion and with steaming after extrusion respectively. Many researchers have reported similar characteristics of cereal starches and flours on amylographs. ${ }^{22-26}$ The changes in pasting characteristics indicate that starch molecules undergo some degree of reassociation during steaming and drying periods. In addition, it is worth noting that there was a small plateau before the onset of gelatinisation viscosity rise (at $45-55^{\circ} \mathrm{C}$ ) on the RVA graphs of the dried rice pasta which was dried directly after extrusion (Fig 1(a)). However, this plateau disappeared when the surface gelatinisation was applied on the extruded rice pasta before drying (Fig 1(b)). This indicates that further reassociation of starch molecules on the surface of extruded rice pasta did take place during hydrothermal treatment, which was applied by steaming at $85^{\circ} \mathrm{C}$ for $1 \mathrm{~h}$ under limited moisture conditions.

\section{Effects of rice properties on cooking quality and colour}

Pasta cooking quality measurements of water absorp-
Figure 1. Effects of blending ratio of GTIndica (Ind) and GTJaponica (Jap) rice flours and steam treatment after extrusion on RVA graphs of rice pasta made therefrom. The raw rice flours were also analysed for comparison, (a) without steam treatment after extrusion, and (b) with steam treatment for $1 \mathrm{~h}$ after extrusion. Inset figures show an enlarged scale in the lowtemperature range.
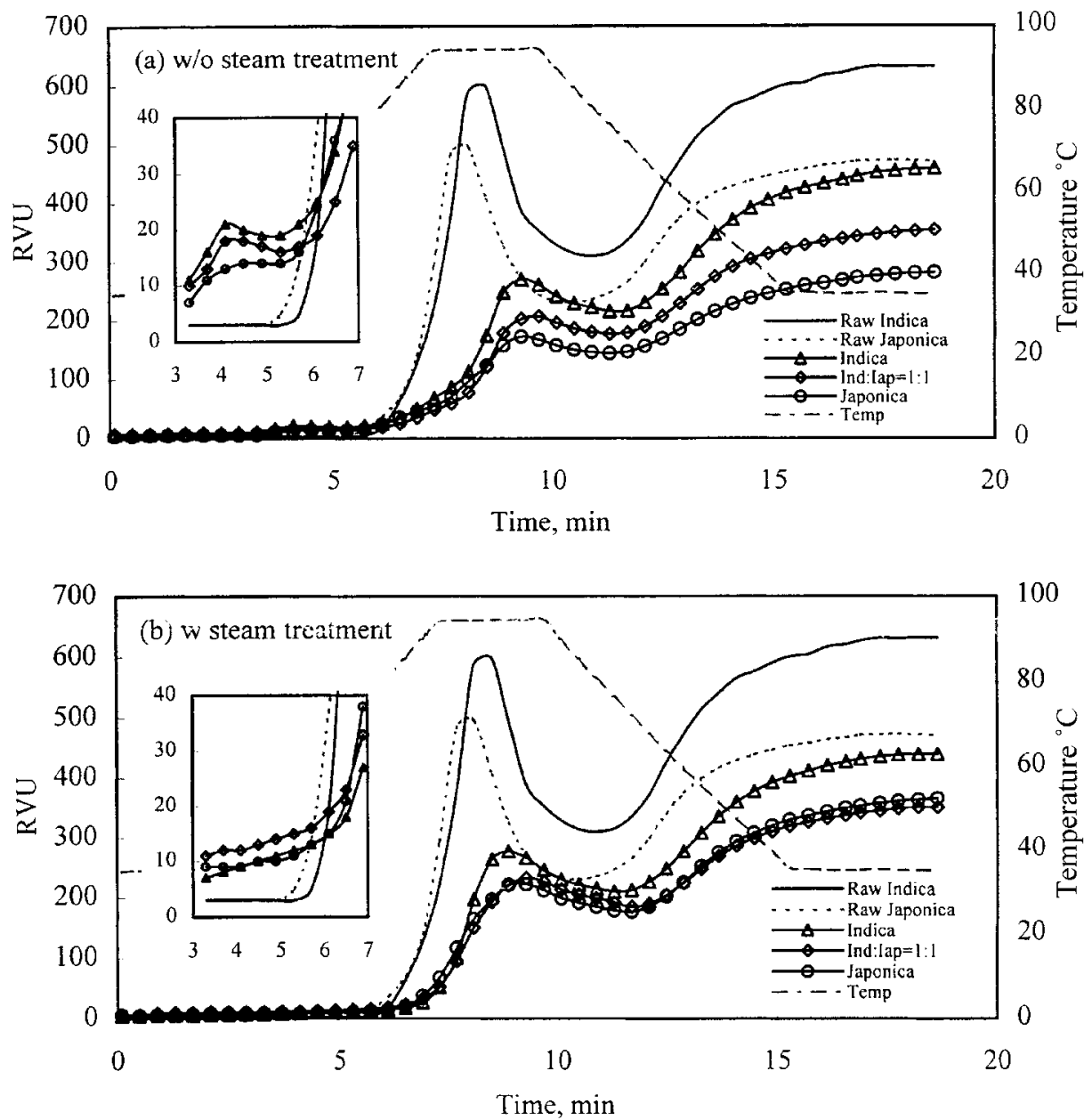
Table 3. Effects of blending ratio of GTIndica (Ind) and GTJaponica (Jap) rice flours on cooking properties and colour of rice pasta made therefrom

\begin{tabular}{lcccc}
\hline $\begin{array}{l}\text { Blending ratio } \\
\text { Ind/Jap }\end{array}$ & Steaming $^{\mathrm{a}}$ & Cooking loss $^{\mathrm{b}}(\%)$ & Weight gain $^{\mathrm{b}}(\%)$ & $\begin{array}{c}\text { Whiteness } \\
\text { index }\end{array}$ \\
\hline $100: 0$ & - & 26 & 93 & 72.7 \\
& + & $18(\downarrow 30.8 \%)$ & $95(\uparrow 2.2 \%)$ & 70.8 \\
$75: 25$ & - & 25 & 95 & 71.2 \\
& + & $17(\downarrow 32.0 \%)$ & $100(\uparrow 5.3 \%)$ & 70.0 \\
$50: 50$ & - & 30 & 97 & 71.5 \\
& + & $19(\downarrow 36.7 \%)$ & $102(\uparrow 5.2 \%)$ & 70.0 \\
$25: 75$ & - & 40 & 101 & 71.3 \\
& + & $23(\downarrow 42.5 \%)$ & $108(\uparrow 6.9 \%)$ & 70.5 \\
$0: 100$ & - & 60 & 106 & 71.2 \\
& + & $33(\downarrow 45.0 \%)$ & $118(\uparrow 11.3 \%)$ & 69.5 \\
\hline
\end{tabular}

a Steam treatment of extruded rice pasta at $100^{\circ} \mathrm{C}$ for $1 \mathrm{~h}$ after extrusion.

${ }^{b}$ Parentheses indicate percentage increase $(\uparrow)$ or decrease $(\downarrow)$ in cooking loss and weight gain of cooked rice pasta. tion, loss of solids to the cooking water and cooking tolerance were the main criteria used for assessing the quality of cooked pasta. Table 3 shows the results obtained for the cooking properties and colour of rice pasta. These results reveal that the cooking loss increased significantly when the amount of GTJaponica rice flour used for rice pasta making was above $500 \mathrm{~g} \mathrm{~kg}^{-1}$. The correlation coefficients between the
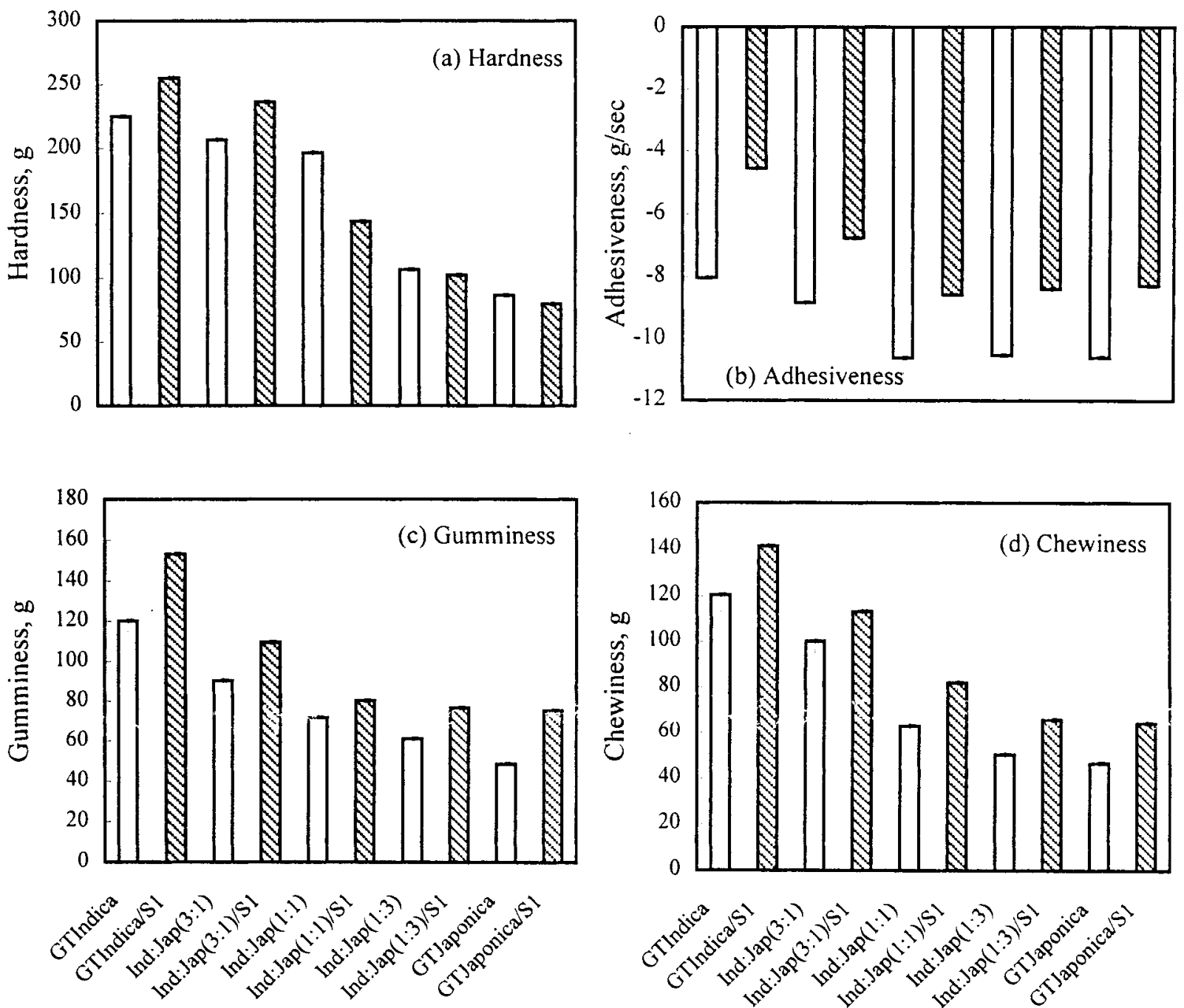

Figure 2. Effects of GTIndica, GTJaponica and their rice flour blends on texture of rice pasta made therefrom. S1 indicates that the rice pasta was steamed at $100^{\circ} \mathrm{C}$ for $1 \mathrm{~h}$ after extrusion. 
amount of GTIndica in blends and cooking loss were -0.90 and -0.87 for rice pasta without steaming after extrusion and with steaming after extrusion respectively. Although a slight increase in the weight gain (water absorption) of cooked rice pasta occurred with an increase in the proportion of GTJaponica rice flour used in blended flours, a serious cooking loss problem resulted in unacceptable rice pasta when the pasta was made from $>500 \mathrm{~g} \mathrm{~kg}^{-1}$ GTJaponica. This high cooking loss is attributable to the higher water solubility (WS) of GTJaponica rice flour, while the large weight gain is attributable to its larger water absorption index (WAI) and swelling power (SP) compared with GTIndica rice flour (Table 2). The results also show that hydrothermal treatment of rice pasta after extrusion significantly decreased its cooking loss, while the maximum recommended amount of GTJaponica rice flour that can be used for blending should not be above $500 \mathrm{~g} \mathrm{~kg}^{-1}$, since it would result in the serious problem of cooking loss. The improvement in the cooking loss of hydrothermally treated rice pasta after extrusion could be attributable to the increase in the stability of the pasta surface due to further reassociation of starch molecules of extruded rice pasta as shown in Fig 1.
The colour of dried rice pasta, expressed as the whiteness index of rice pasta, decreased with an increase in the amount of GTJaponica rice flour blended. Similar results were reported by Umali. ${ }^{13}$ Hydrothermal treatment significantly decreased the whiteness of rice pasta and produced a deep brown colour of rice pasta when GTJaponica rice flour only was used for hydrothermal treatment after extrusion.

\section{Effects of rice properties on texture}

The effects of rice properties on the texture of cooked rice pasta are shown in Fig 2. Generally speaking, the hardness, gumminess and chewiness of cooked rice pasta decreased with an increase in the proportion of GTJaponica rice flour that was blended in. Steam treatment of extruded rice pasta before drying increased the hardness, gumminess and chewiness of cooked rice pasta significantly, while it decreased the adhesiveness of cooked rice pasta significantly. However, pasta made from rice flour blended with up to $500 \mathrm{~g} \mathrm{~kg}^{-1}$ GTJaponica was too soft, soggy and adhesive to maintain a good pasta shape, resulting in an unsatisfactory product.
Figure 3. Effects of emulsifiers on RVA graphs of rice pasta made from GTIndica rice flour, (a) without steam treatment, and (b) with steam treatment after extrusion. GMS, DIMODAN PM; $\mathrm{KM}, \mathrm{KM} 3000$. Inset figures show an enlarged scale in the low-temperature range.
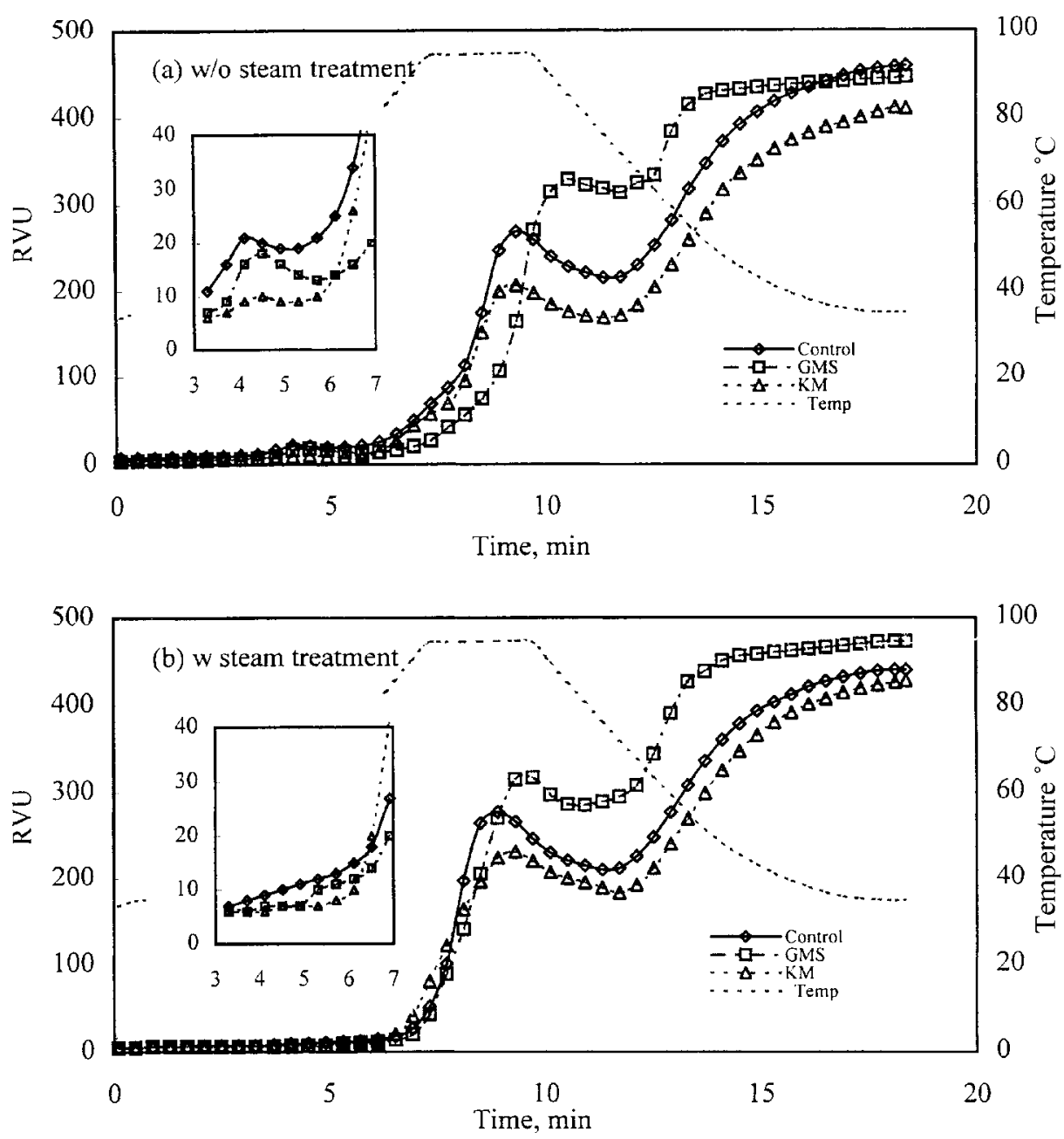


\section{Effects of emulsifiers on pasting properties}

The effects of emulsifiers on the pasting curve of dried rice pasta made from GTIndica, GTIndica/GTJaponica 1:1 and GTJaponica rice flours are shown in Figs 3-5 respectively. The pasting curves of dried rice pasta made from GTIndica rice flour were significantly affected by the type of emulsifier used (Fig 3). DAMODAN PM (distilled glyceryl monosterate, GMS) delayed $T_{\mathrm{o}}$, increased PV and decreased BDV and TSBV. In contrast, KM3000 slightly lowered $T_{\mathrm{o}}$ and decreased PV. The differences in the way emulsifiers modify the pasting curve are responsible for their various amylose-complexing effects. ${ }^{27} \mathrm{Krog}^{28}$ compared the modification effects of three emulsifiers ( $5 \mathrm{~g} \mathrm{~kg}^{-1}$ DATEM, SSL or GMS) on the gelatinisation behaviour of wheat starch. He pointed out that DATEM is the least interactive, while GMS causes dramatic changes. GMS raises the swelling temperature by $18^{\circ} \mathrm{C}$ and also increases the paste viscosity. The formation of emulsifier-amylose complexes results in changes in water transport into starch granules. If these complexes are formed on the surface of the starch granule, an insoluble film might result, which would delay starch gelatinisation during cooking. In contrast with the increase in PV observed in this study, Ryu and Walker ${ }^{29}$ reported that PV of wheat flour extrudates decreased with increasing concentrations of GMS from 0 to $7.5 \mathrm{~g} \mathrm{~kg}^{-1}$. The decrease in PV with the addition of GMS is explained by the presence of amylose-emulsifier complexes on the starch granular surface that resulted in the restriction of swelling. In contrast, the opposite effects of GMS on PV observed in this study could have been due to the mild processing conditions (low temperature, low shearing and short residence time) used for making rice pasta. Rice pasta samples in this study were hydrothermally treated under conditions of limited moisture content $\left(400 \mathrm{~g} \mathrm{~kg}^{-1}\right)$, low steaming temperature $\left(85^{\circ} \mathrm{C}\right)$, short steaming time $(10 \mathrm{~min})$ and extrusion at a low temperature $\left(<50^{\circ} \mathrm{C}\right)$, so that most of the emulsifier-starch complexes were mainly formed not during extrusion but during the RVA cooking period (Fig 3(a)). $\mathrm{Xu}$ et $a l^{30}$ also observed the existence of a plateau before the onset of gelatinisation viscosity rise and considered it to represent the effects of the specific amylogram characteristics of wheat flours containing wheat flour polar lipids or emulsifiers. In the present study this plateau disappeared when the surface gelatinisation was applied on the extruded rice pasta before drying (Fig 3(b)) as shown in Fig 1(b).

When rice pastas were made with GTIndica/ GTJaponica 1:1 blended rice flour or with GTJapo-
Figure 4. Effects of emulsifiers on RVA graphs of rice pasta made from GTIndica/GTJaponica 1:1 rice flour, (a) without steam treatment, and (b) with steam treatment after extrusion. GMS, DIMODAN PM; KM, KM3000. Inset figures show an enlarged scale in the low-temperature range.
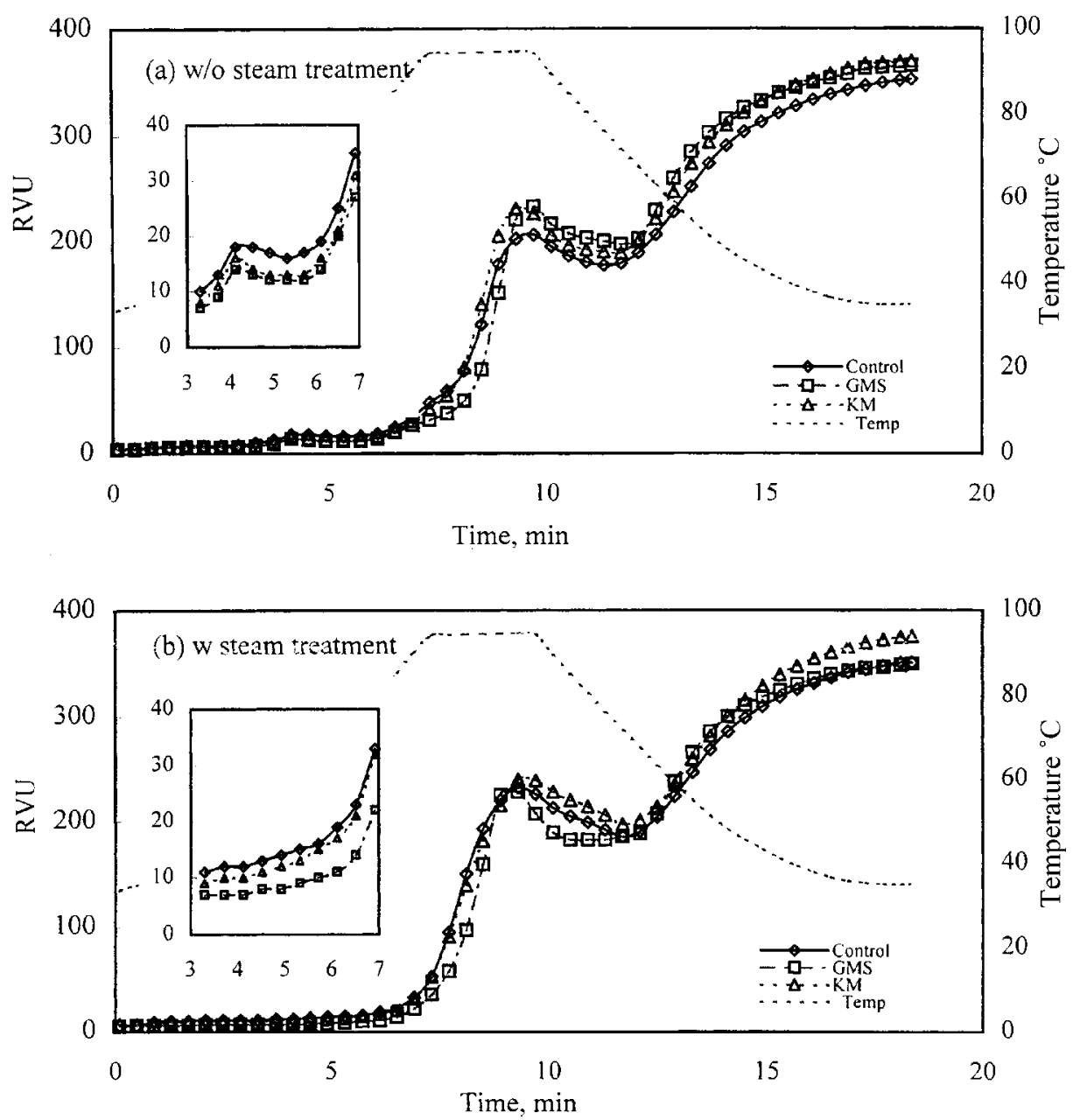


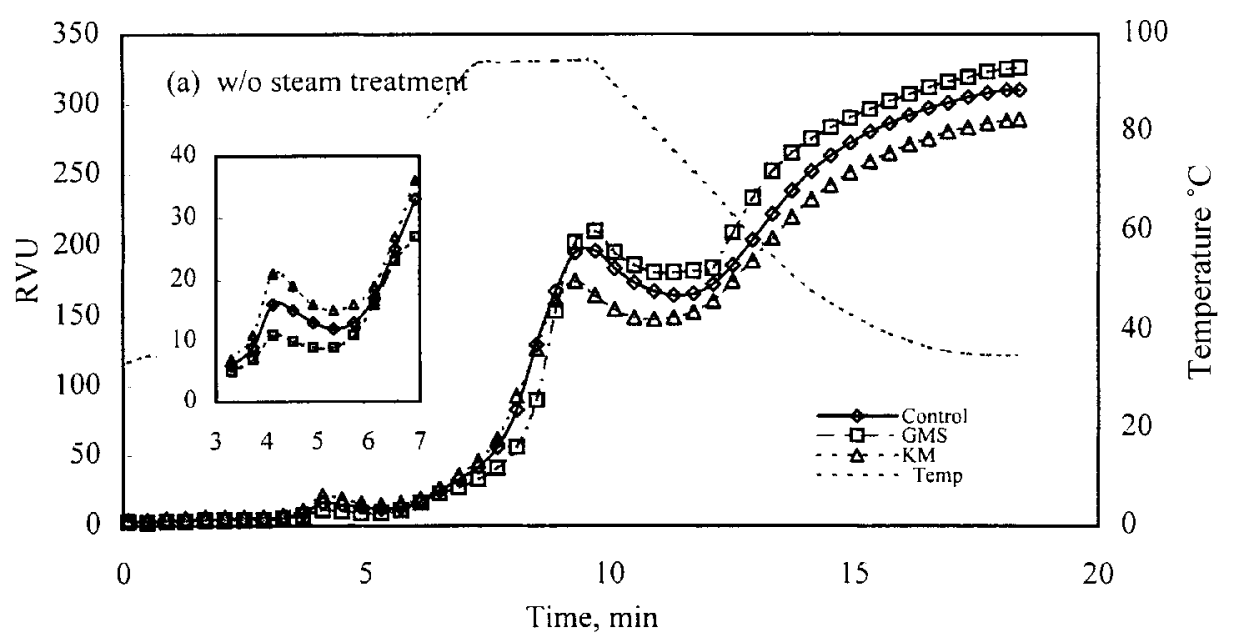

Figure 5. Effects of emulsifiers on RVA graphs of rice pasta made from GTJaponica rice flour, (a) without steam treatment, and (b) with steam treatment after extrusion. GMS, DIMODAN PM; KM, KM3000. Inset figures show an enlarged scale in the

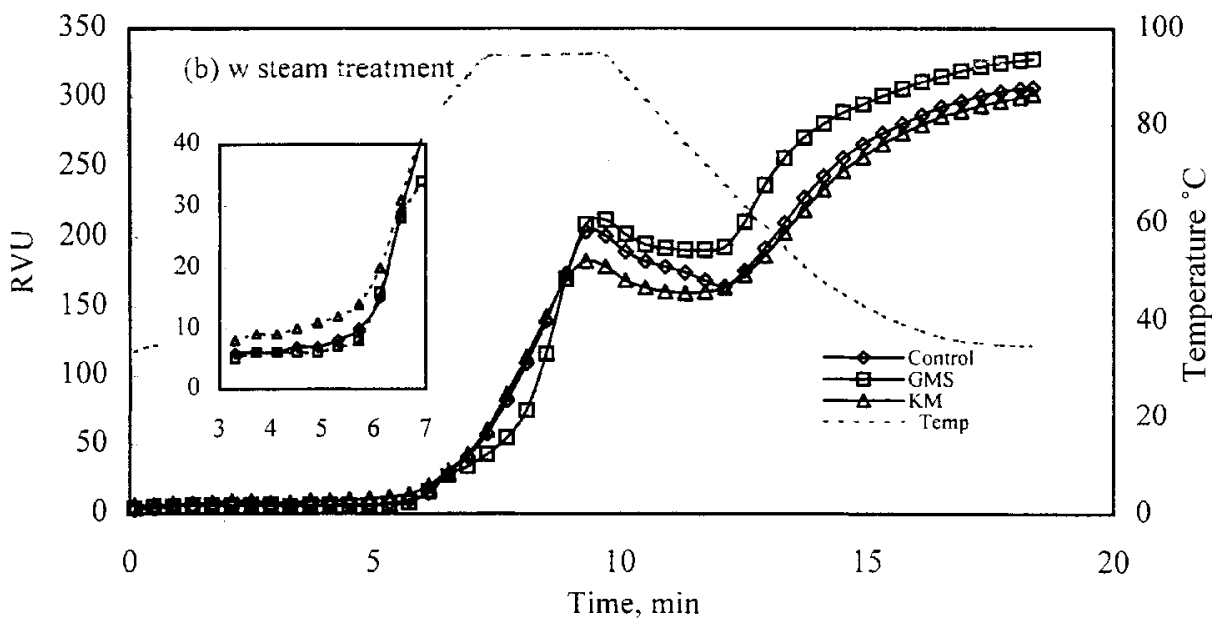

low-temperature range.

nica rice flour alone, the pasting curves were not significantly affected by the type of emulsifier (Figs 4 and 5), unlike when GTIndica rice flour alone was used (Fig 3). Figs 4(b) and 5(b) show that similar results were obtained on steam treatment after extrusion on the rice pasta amylographs as shown in Fig 1(b). These results included the disappearance of a small plateau at low temperature $\left(45-55^{\circ} \mathrm{C}\right)$ and lowered $T_{\mathrm{g}}$ when extruded rice pasta was steamed for $1 \mathrm{~h}$ before drying. The properties of GTJaponica rice flour, ie low gelatinisation temperature, high SP and high WS (Table 2), give the rice pasta a higher degree of gelatinisation and result in more soluble amylose leaching out during rice pasta making than with GTIndica rice flour. Thus the emulsifier-soluble amylose complexes are mainly formed during rice pasta making when GTJaponica rice flour is used and during pasta cooking when GTIndica rice flour is used.

\section{Effects of emulsifiers on cooking properties and colour}

The effects of emulsifiers on the cooking properties and colour of rice pasta made with GTIndica, GTJaponica and their 1:1 blend are summarised in Table 4. The results indicate that $10 \mathrm{~g} \mathrm{~kg}^{-1}$ GMS improved the cooking properties of rice pasta, especially for pasta made with GTIndica rice flour. The GMS-amylose complex formation during cooking reduced the extent of solubilisation of starch molecules upon heating in excess water. ${ }^{31}$ This resulted in a decrease in cooking loss and an increase in cooking weight gain of cooked rice pasta made from GTIndica rice flour (correlation coefficient $r=0.96$ ). The complex formed mainly during the cooking stage and overcame the swelling restriction effect on the starch granules due to the emulsifiers. Steam treatment of extruded rice pasta before drying also improved the cooking properties of all the different samples of rice pasta by decreasing the cooking loss and increasing the cooking weight gain. The cooking loss of rice pasta made from GTIndica rice flour was decreased by up to $56 \%$ and the cooking weight gain was increased by up to $79 \%$ when $10 \mathrm{~g} \mathrm{~kg}^{-1}$ GMS was added to the rice flour dough and the extruded rice pasta was steamed before drying. Although the addition of emulsifier and steam treatment could improve the cooking properties of cooked rice pasta, the low cooking tolerance of rice pasta made from GTJaponica was still unacceptable. In general, a creamy white, opaque cooked rice pasta was obtained when GMS was added, while yellowish, transparent 
Table 4. Effects of emulsifiers $\left(10 \mathrm{~g} \mathrm{~kg}^{-1}\right)$ on cooking properties and colour of rice pasta made from pure and blended GTIndica (Ind) and GTJaponica (Jap) rice flours

\begin{tabular}{|c|c|c|c|c|c|}
\hline $\begin{array}{l}\text { Blending ratio } \\
\text { Ind/Jap }\end{array}$ & Steaming $^{\text {a }}$ & Emulsifier $^{\mathrm{b}}$ & Cooking loss ${ }^{\mathrm{C}}(\%)$ & Weight gain ${ }^{\mathrm{C}}(\%)$ & $\begin{array}{c}\text { Whiteness } \\
\text { index }\end{array}$ \\
\hline \multirow[t]{6}{*}{$100: 0$} & - & - & 26 & 93 & 72.7 \\
\hline & + & - & $18(\downarrow 30.8 \%)$ & $95(\uparrow 2.2 \%)$ & 70.8 \\
\hline & - & GMS & $13(\downarrow 50.0 \%)$ & $155(\uparrow 66.7 \%)$ & 73.8 \\
\hline & + & GMS & $11(\downarrow 57.7 \%)$ & $166(\uparrow 78.5 \%)$ & 72.6 \\
\hline & - & KM & $22(\downarrow 15.4 \%)$ & $110(\uparrow 18.3 \%)$ & 73.1 \\
\hline & + & KM & $18(\downarrow 30.8 \%)$ & $135(\uparrow 45.2 \%)$ & 72.1 \\
\hline \multirow[t]{6}{*}{$50: 50$} & - & - & 30 & 97 & 71.5 \\
\hline & + & - & $19(\downarrow 36.7 \%)$ & $102(\uparrow 5.2 \%)$ & 70.0 \\
\hline & - & GMS & $25(\downarrow 17.7 \%)$ & $128(\uparrow 31.9 \%)$ & 72.3 \\
\hline & + & GMS & $20(\downarrow 33.3 \%)$ & $132(\uparrow 36.1 \%)$ & 71.3 \\
\hline & - & $\mathrm{KM}$ & $28(\downarrow 6.7 \%)$ & $101(\uparrow 4.1 \%)$ & 72.1 \\
\hline & + & KM & $23(\downarrow 23.3 \%)$ & $121(\uparrow 24.7 \%)$ & 70.6 \\
\hline \multirow[t]{6}{*}{$0: 100$} & - & - & 60 & 106 & 70.9 \\
\hline & + & - & $33(\downarrow 45.0 \%)$ & $118(\uparrow 11.3 \%)$ & 70.0 \\
\hline & - & GMS & $39(\downarrow 35.0 \%)$ & $102(\downarrow 3.8 \%)$ & 72.6 \\
\hline & + & GMS & $31(\downarrow 48.3 \%)$ & $119(\uparrow 12.3 \%)$ & 71.6 \\
\hline & - & KM & $46(\downarrow 23.3 \%)$ & $95(\downarrow 10.4 \%)$ & 72.6 \\
\hline & + & KM & $42(\downarrow 30.0 \%)$ & $97(\downarrow 8.5 \%)$ & 71.3 \\
\hline
\end{tabular}

a Steam treatment of extruded rice pasta at $100^{\circ} \mathrm{C}$ for $1 \mathrm{~h}$ after extrusion.

b GMS; DIMODAN PM; KM, KM3000.

c Parentheses indicate percentage increase $(\uparrow)$ or decrease $(\downarrow)$ in cooking loss and weight gain of cooked rice pasta. cooked rice pasta was obtained upon adding KM3000. In addition, steam treatment darkened the colour of rice pasta significantly.

\section{Effects of emulsifiers on thermal properties}

The thermal properties of dried rice pasta were evaluated using DSC, and the results are shown in Table 5. The gelatinisation enthalpy $\left(\Delta H_{1}\right)$ of rice pasta with steam treatment after extrusion was smaller than that of rice pasta without steam treatment. This indicates that starch was further gelatinised during $1 \mathrm{~h}$ of steaming, especially the surface starch. This caused

Table 5. Effects of emulsifiers $\left(10 \mathrm{~g} \mathrm{~kg}^{-1}\right)$ on thermal properties of rice pasta made from pure and blended GTIndica (Ind) and GTJaponica (Jap) rice flours

\begin{tabular}{|c|c|c|c|c|c|c|c|c|c|c|c|}
\hline \multirow[b]{2}{*}{$\begin{array}{l}\text { Blending ratio } \\
\text { Ind/Jap }\end{array}$} & \multirow[b]{2}{*}{ Steaming ${ }^{a}$} & \multirow[b]{2}{*}{ Emulsifier $^{\mathrm{b}}$} & \multicolumn{3}{|c|}{ 1st peak } & \multicolumn{3}{|c|}{ 2nd peak } & \multicolumn{3}{|c|}{ 3rd peak } \\
\hline & & & $T_{10}\left({ }^{\circ} \mathrm{C}\right)$ & $T_{1 p}\left({ }^{\circ} \mathrm{C}\right)$ & $\begin{array}{c}\Delta H_{1} \\
\left(J g^{-1}, d b\right)\end{array}$ & $T_{20}\left({ }^{\circ} \mathrm{C}\right)$ & $T_{2 p}\left({ }^{\circ} C\right)$ & $\begin{array}{c}\Delta H_{2} \\
\left(J g^{-1}, d b\right)\end{array}$ & $T_{30}\left({ }^{\circ} \mathrm{C}\right)$ & $T_{3 p}\left({ }^{\circ} \mathrm{C}\right)$ & $\begin{array}{c}\Delta H_{3} \\
\left(J g^{-1}, d b\right)\end{array}$ \\
\hline \multirow{6}{*}{$100: 0$} & - & - & 67.9 & 78.1 & 2.6 & 90.1 & 98.3 & 1.5 & - & - & - \\
\hline & + & - & 73.1 & 82.0 & 0.6 & 89.7 & 96.7 & 2.1 & - & - & - \\
\hline & - & GMS & 78.2 & 82.6 & 3.6 & 91.6 & 100.0 & 2.0 & 118.2 & 122.6 & 1.2 \\
\hline & + & GMS & 80.7 & 87.1 & 2.4 & 93.2 & 99.4 & 1.2 & 117.2 & 120.1 & 0.7 \\
\hline & - & $\mathrm{KM}$ & 74.5 & 80.0 & 3.0 & 93.1 & 98.1 & 1.4 & 107.5 & 111.2 & 0.4 \\
\hline & + & $\mathrm{KM}$ & 79.1 & 83.9 & 2.0 & 93.5 & 98.0 & 0.7 & 105.9 & 112.4 & 0.4 \\
\hline \multirow[t]{6}{*}{$50: 50$} & - & - & 66.5 & 71.9 & 1.5 & 85.3 & 91.1 & 2.6 & - & - & - \\
\hline & + & - & 70.3 & 75.6 & 0.9 & 85.8 & 91.1 & 1.3 & - & - & - \\
\hline & - & GMS & 76.4 & 81.3 & 2.0 & 93.1 & 99.4 & 2.5 & 96.0 & 100.3 & 0.9 \\
\hline & + & GMS & 78.2 & 84.8 & 1.1 & 95.8 & 104.7 & 0.6 & 117.0 & 119.8 & 0.4 \\
\hline & - & $\mathrm{KM}$ & 69.9 & 82.6 & 2.9 & 94.6 & 99.3 & 1.1 & 110.8 & 112.3 & 0.1 \\
\hline & + & $\mathrm{KM}$ & 77.2 & 80.8 & 0.6 & 95.8 & 99.9 & 0.7 & 108.2 & 110.6 & 0.4 \\
\hline \multirow[t]{6}{*}{$0: 100$} & - & - & - & - & - & 90.7 & 100.4 & 2.9 & - & - & - \\
\hline & + & - & - & - & - & 91.6 & 98.5 & 2.0 & - & - & - \\
\hline & - & GMS & 68.5 & 76.9 & 1.5 & 93.3 & 101.1 & 1.4 & - & - & - \\
\hline & + & GMS & 74.5 & 80.2 & 1.2 & 92.3 & 99.3 & 1.6 & - & - & - \\
\hline & - & $\mathrm{KM}$ & 69.7 & 77.6 & 1.7 & 93.2 & 100.6 & 2.8 & - & - & - \\
\hline & + & $\mathrm{KM}$ & 83.4 & 89.9 & 0.8 & 97.1 & 100.7 & 0.7 & - & - & - \\
\hline
\end{tabular}

a Steam treatment of extruded rice pasta at $100^{\circ} \mathrm{C}$ for $1 \mathrm{~h}$ after extrusion.

b GMS, DIMODAN PM; KM, KM3000. 
a gelatinised starch film to form on the surface of rice pasta and improved the cooking tolerance (Table 4). The large gelatinisation enthalpy and high gelatinisation onset temperature $\left(T_{10}\right)$ of rice pasta after the addition of emulsifiers indicated that the presence of emulsifier significantly influences the gelatinisation behaviour of rice pasta. The greater emulsifieramylose complex enthalpy $\left(\Delta H_{2}\right.$ and $\left.\Delta H_{3}\right)$ of dried rice pasta after GMS addition indicates that GMS has a stronger interaction with the amylose than KM3000.

\section{Effects of emulsifiers on texture}

The addition of emulsifiers to rice flour when making rice pasta influences not only the flowability of rice flour during the extrusion process but also the texture of cooked rice pasta. Significant improvement in the smoothness of the extrusion process was observed when GMS was added in quantities as low as $5 \mathrm{~g} \mathrm{~kg}^{-1}$. The effects of emulsifiers on the texture of cooked rice pasta depended on the properties of the rice flour used and whether steam treatment was done after the application of extrusion (Table 6).

GMS significantly decreased the hardness of rice pasta made from GTIndica rice flour. KM3000 also decreased the hardness but to a lesser extent than GMS. The increase in hardness of rice pasta made from GTIndica and steamed for $1 \mathrm{~h}$ after extrusion but before drying is attributed to the gelatinisation of surface starch of rice pasta during steam treatment, which caused a tough starch film to form on the surface of the pasta, while hardening of rice pasta through steam treatment after extrusion was not observed for rice pasta made with the addition of emulsifiers. This is attributable to the limited amount of starch granules undergoing further gelatinisation or less amylose leaching out to form a starch film. Because emulsifier, especially GMS, was complexed with amylose efficiently, it also restricted starch swelling and thus decreased the solubility of amylose. Therefore the surface strength of cooked rice pasta was lower than that without emulsifier and lower than that with emulsifier but without steam treatment.

For the rice pasta made from GTIndica/GTJaponica 1:1 blended rice flour, the addition of emulsifier decreased the hardness of cooked rice pasta. However, the texture of cooked rice pasta was not significantly influenced by steam treatment of extruded rice pasta before drying. For the rice pasta made from GTJaponica rice flour, although the addition of KM 3000 significantly improved its cooking properties, the resulting pasta was soft, adhesive and had a gummy texture which was still unacceptable.

Although the addition of emulsifier would be expected to reduce the stickiness of cooked rice pasta, a significant reduction in the adhesiveness of cooked rice pasta was only observed in the pasta made from GTIndica rice flour with the addition of GMS. For the rice pasta made from GTJaponica rice flour or the
Table 6. Effects of emulsifiers on texture of rice pasta made from pure and blended GTIndica (Ind) and GTJaponica (Jap) rice flours ${ }^{a}$

\begin{tabular}{|c|c|c|c|c|}
\hline $\begin{array}{l}\text { Blending ratio } \\
\text { Ind/Jap }\end{array}$ & Steaming ${ }^{\mathrm{b}}$ & $\begin{array}{l}\text { Emulsifier }^{\mathrm{c}} \\
\left(g k \mathrm{~g}^{-1}\right)\end{array}$ & $\begin{array}{l}\text { Hardness } \\
\text { (g) }\end{array}$ & $\begin{array}{c}\text { Adhesiveness } \\
\left(g \mathrm{~mm}^{-2}\right)\end{array}$ \\
\hline \multirow[t]{10}{*}{$100: 0$} & - & - & $224.6 \pm 11.4 b$ & $-8.04 \pm 0.50 \mathrm{e}$ \\
\hline & + & - & $254.9 \pm 15.2 a$ & $-4.57 \pm 0.77 b$ \\
\hline & - & GMS (5) & $173.6 \pm 7.7 e$ & $-5.45 \pm 0.58 c$ \\
\hline & + & GMS (5) & $154.0 \pm 4.6 f$ & $-7.10 \pm 0.61 d$ \\
\hline & - & GMS (10) & $148.1 \pm 5.6 f$ & $-2.32 \pm 0.71 a$ \\
\hline & + & GMS (10) & $136.7 \pm 8.0 \mathrm{~g}$ & $-2.71 \pm 0.60 a$ \\
\hline & - & KM (10) & $188.9 \pm 7.6 \mathrm{~d}$ & $-8.21 \pm 0.44 \mathrm{e}$ \\
\hline & + & KM (10) & $218.8 \pm 6.9 b$ & $-8.49 \pm 0.78 e$ \\
\hline & - & KM (20) & $202.3 \pm 7.3 c$ & $-5.29 \pm 0.53 c$ \\
\hline & + & KM (20) & $207.2 \pm 9.2 c$ & $-11.16 \pm 0.68$ \\
\hline \multirow[t]{6}{*}{$50: 50$} & - & - & $196.4 \pm 11.5 a$ & $-10.63 \pm 0.54 b$ \\
\hline & + & - & $143.7 \pm 8.0 c$ & $-8.58 \pm 0.29 a$ \\
\hline & - & GMS (10) & $157.8 \pm 4.8 b$ & $-17.08 \pm 1.11 \mathrm{e}$ \\
\hline & + & GMS (10) & $142.6 \pm 4.3 c$ & $-12.86 \pm 1.31 c$ \\
\hline & - & KM (10) & $161.6 \pm 4.2 b$ & $-14.84 \pm 0.49 d$ \\
\hline & + & KM (10) & $156.0 \pm 5.1 b$ & $-16.51 \pm 0.34 e$ \\
\hline \multirow[t]{6}{*}{$0: 100$} & - & - & $86.5 \pm 5.2 c$ & $-8.12 \pm 0.60 a$ \\
\hline & + & - & $80.0 \pm 4.9 d$ & $-8.29 \pm 0.59 a$ \\
\hline & - & GMS (10) & $79.9 \pm 4.0 d$ & $-16.36 \pm 0.52 c$ \\
\hline & + & GMS (10) & $80.1 \pm 3.6 d$ & $-12.52 \pm 0.90 b$ \\
\hline & - & KM (10) & $107.2 \pm 4.2 b$ & $-19.67 \pm 0.77 d$ \\
\hline & + & KM (10) & $114.3 \pm 5.2 a$ & $-23.87 \pm 2.60 \mathrm{e}$ \\
\hline
\end{tabular}

a Mean values in the same column (within the same rice blending group) with different letters are significantly different at $p<0.05$.

${ }^{b}$ The rice pasta formed was steamed at $100^{\circ} \mathrm{C}$ for $1 \mathrm{~h}$ after extrusion.

c GMS, DIMODAN PM; KM, KM3000. 
blended rice flour, the adhesiveness of cooked rice pasta was not reduced but increased. This finding is attributable to the stickiness characteristic of cooked low-amylose rice and to the adhesive properties of emulsifier that is free to form a complex with amylose.

\section{Microstructure of rice pasta}

Figs $6-8$ are SEM photographs of rice pasta made from GTIndica, GTIndica/GTJaponica $1: 1$ and GTJaponica rice flours respectively with or without steam treatment and $5 \mathrm{~g} \mathrm{~kg}^{-1}$ GMS addition. The degree of surface starch gelatinisation of rice pasta made from the various rice flours was in the follow- ing order: GTJaponica > GTIndica/GTJaponica 1:1> GTIndica (Figs 6(a), 7(a) and 8(a)). Steam treatment after extrusion caused obvious further gelatinisation of the starch granules at the surface of extruded rice pasta (Figs 6(c), 7(c) and 8(c)). Numerous small starch granules were observed in rice pasta made by the addition of $5 \mathrm{~g} \mathrm{~kg}^{-1} \mathrm{GMS}$, especially for the rice pasta made with GTIndica rice flour (Fig 6(b)). This indicated that GMS significantly restricted the swelling of starch granules and that it may retard starch gelatinisation. ${ }^{32}$ The retardation of starch gelatinisation due to the addition of emulsifiers was also shown by the increase in its gelatinisation temperature

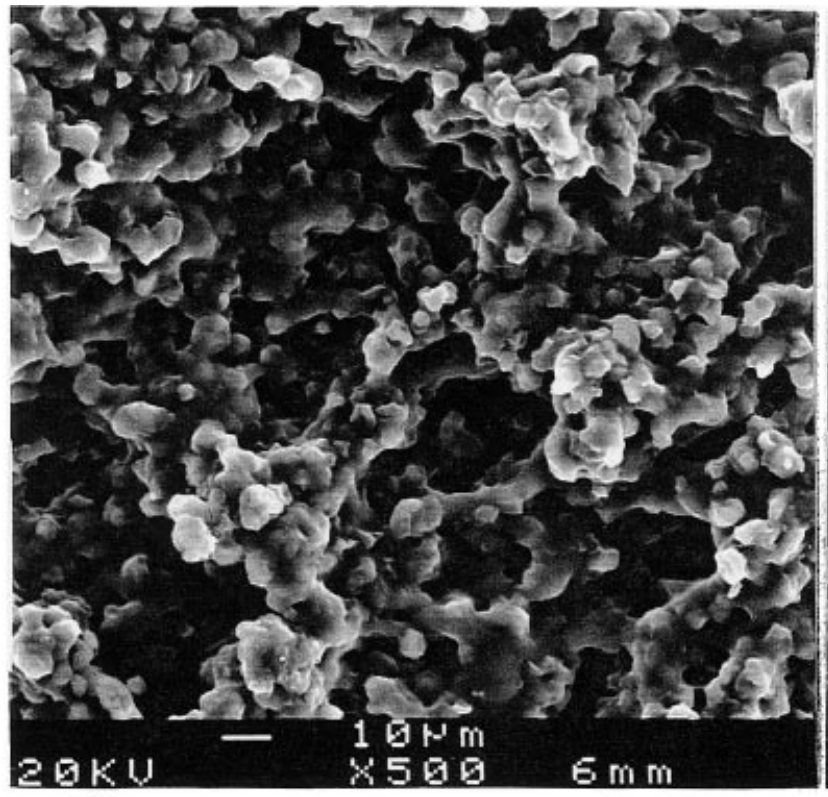

(a)

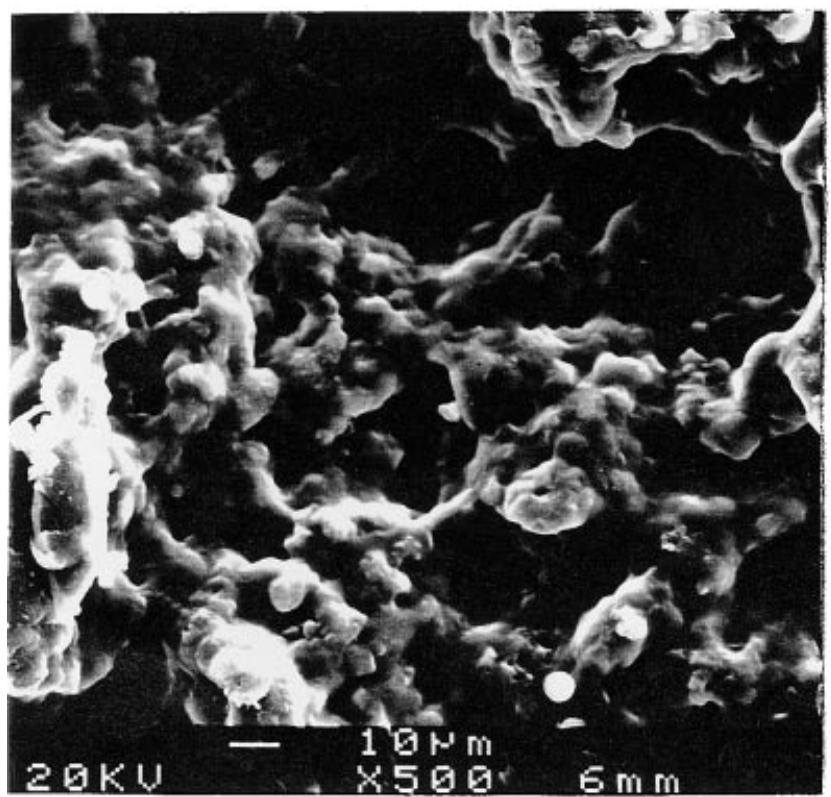

(c)

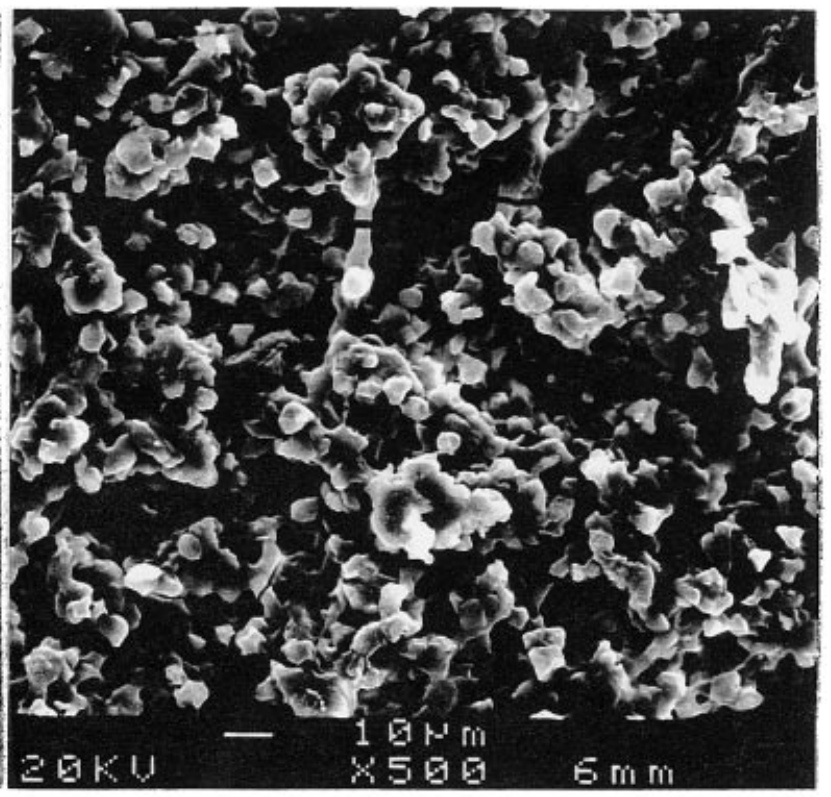

(b)

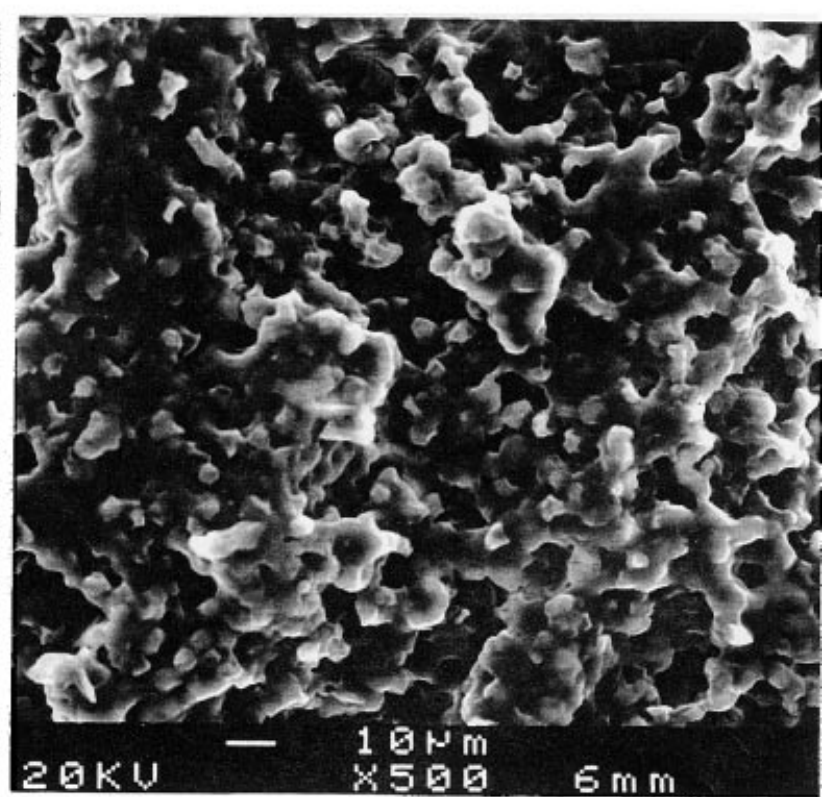

(d)

Figure 6. SEM photographs of surface of rice pasta made from GTIndica rice flour, (a) without emulsifier addition and dried directly, (b) without emulsifier addition but steamed at $100^{\circ} \mathrm{C}$ for $1 \mathrm{~h}$ after extrusion, (c) with addition of $5 \mathrm{~g} \mathrm{~kg}^{-1}$ GMS DIMODAN PM and dried directly, and (d) with addition of $5 \mathrm{~g} \mathrm{~kg}$-1 GMS DIMODAN PM but steamed at $100^{\circ} \mathrm{C}$ for $1 \mathrm{~h}$ after extrusion. 
observed by RVA (Fig 3). Restriction of starch swelling with the addition of emulsifiers is desirable for rice pasta, because it can maintain the shape of cooked rice pasta and improve its cooking tolerance (Table 4). However, the use of rice flours with the properties of high degree of starch gelatinisation and low rigidity of starch granules during processing and cooking results in a soft, adhesive, gummy and lowchewy texture of rice pasta (Fig 8). Therefore GTJaponica rice flour alone is not suitable for making rice pasta by applying the processes utilised in this study.

\section{CONCLUSIONS}

Processing procedures for making acceptable rice pasta products from high-amylose (GTIndica) rice flour alone or by blending with up to $500 \mathrm{~g} \mathrm{~kg}^{-1}$ lowamylose (GTJaponica) rice flour were established. Steam treatment of extruded rice pasta before drying and emulsifier addition significantly improved the cooking properties of cooked rice pasta. A decrease in cooking loss and increase in weight gain of cooked rice pasta resulted from the formation of an emulsifieramylose complex during steaming and cooking. In addition, adding a small amount of emulsifier

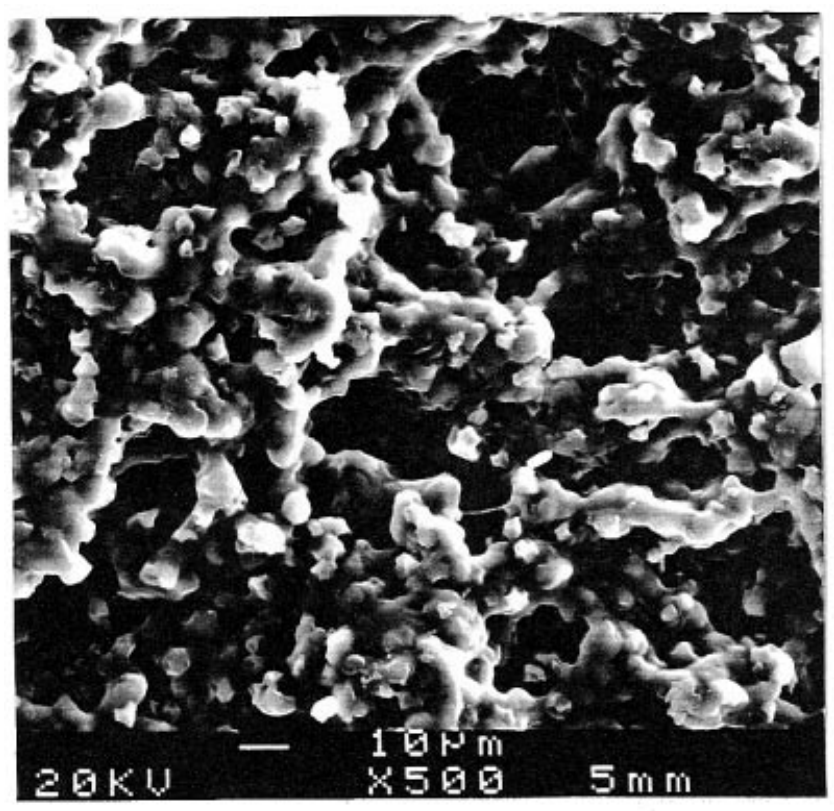

(a)

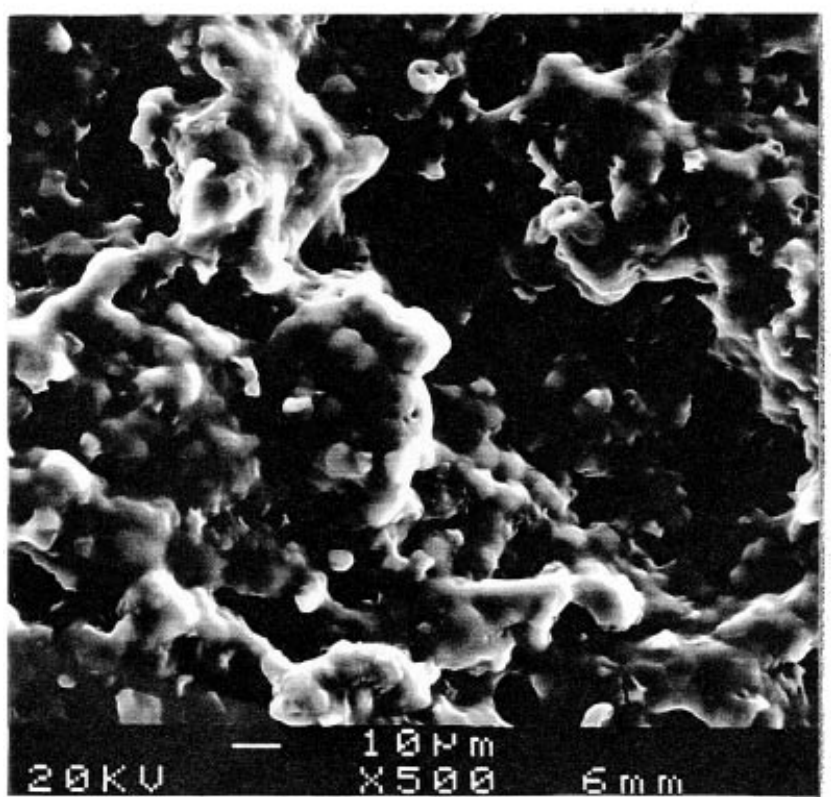

(c)

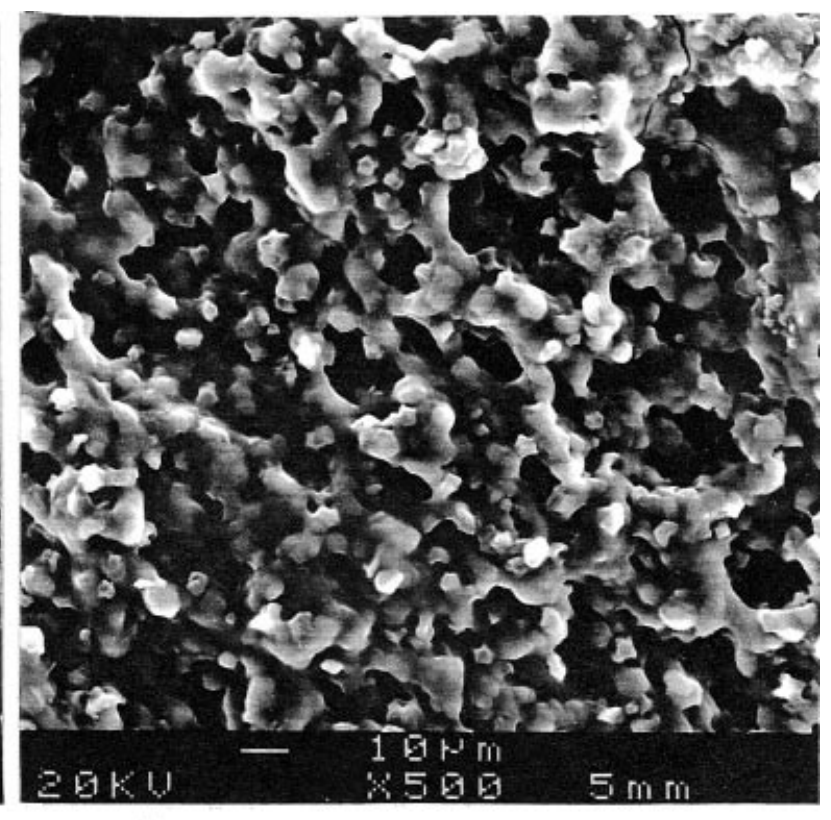

(b)

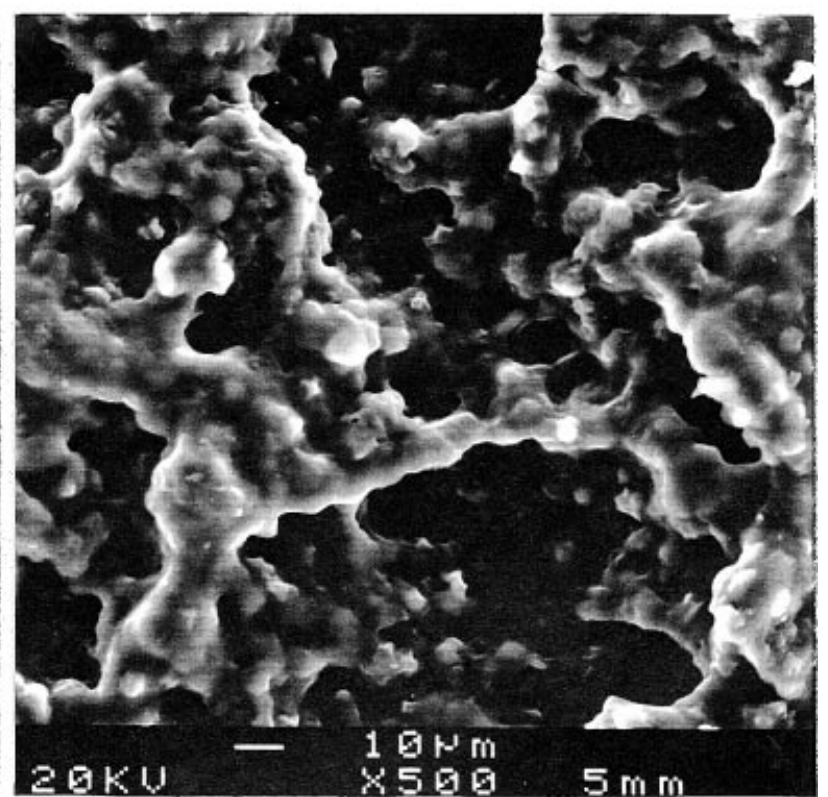

(d)

Figure 7. SEM photographs of surface of rice pasta made from GTIndica/GTJaponica 1:1 rice flour, (a) without emulsifier addition and dried directly, (b) without emulsifier addition but steamed at $100^{\circ} \mathrm{C}$ for $1 \mathrm{~h}$ after extrusion, (c) with addition of $5 \mathrm{~g} \mathrm{~kg}^{-1}$ GMS DIMODAN PM and dried directly, and (d) with addition of $5 \mathrm{~g} \mathrm{~kg}^{-1} \mathrm{GMS}$ DIMODAN PM but steamed at $100^{\circ} \mathrm{C}$ for $1 \mathrm{~h}$ after extrusion. 


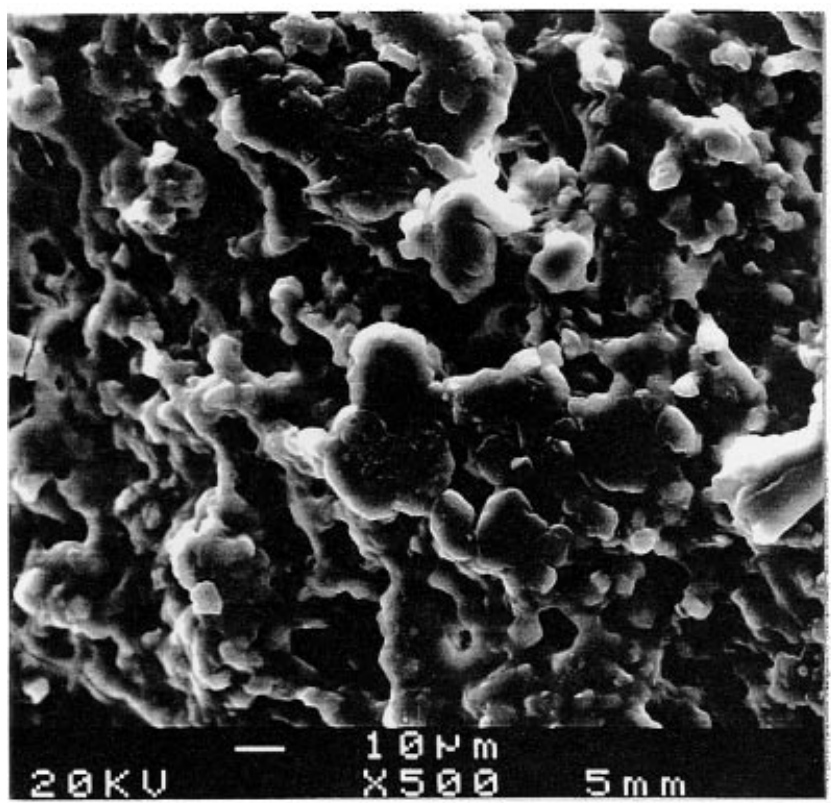

(a)

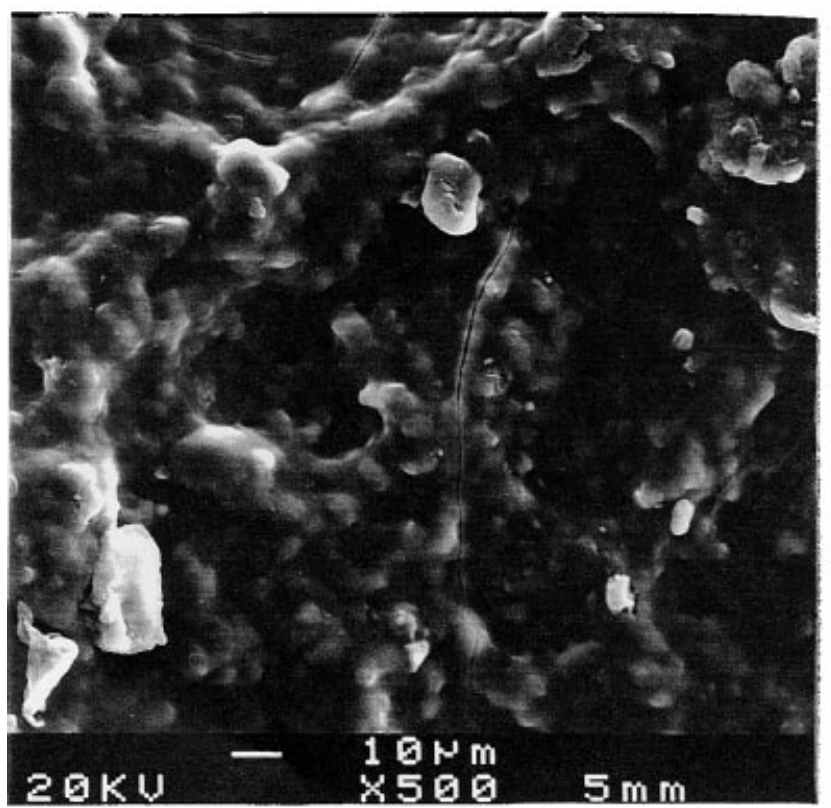

(c)

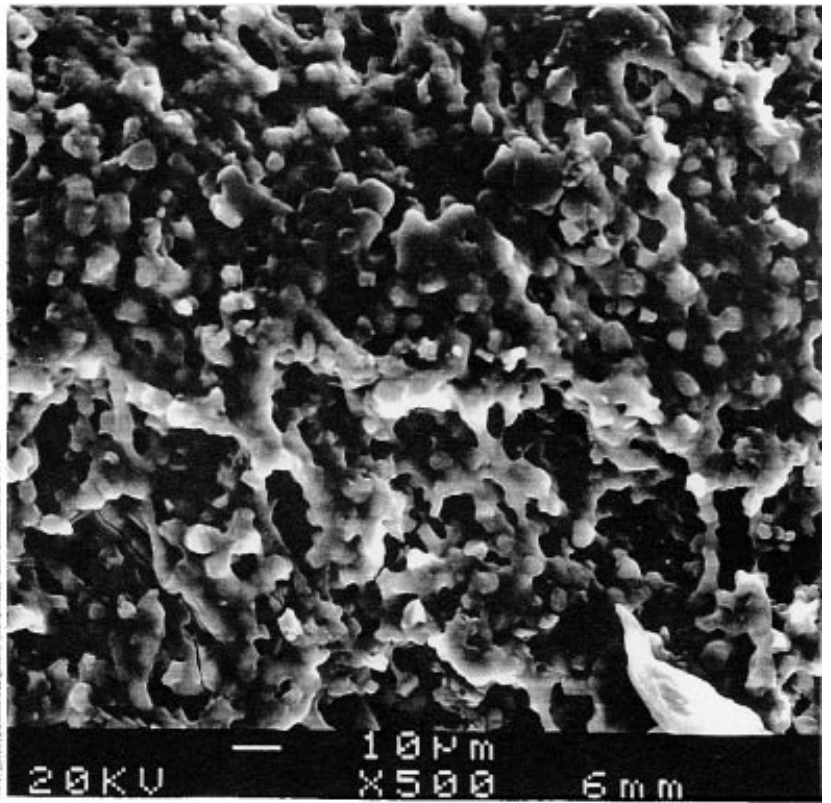

(b)

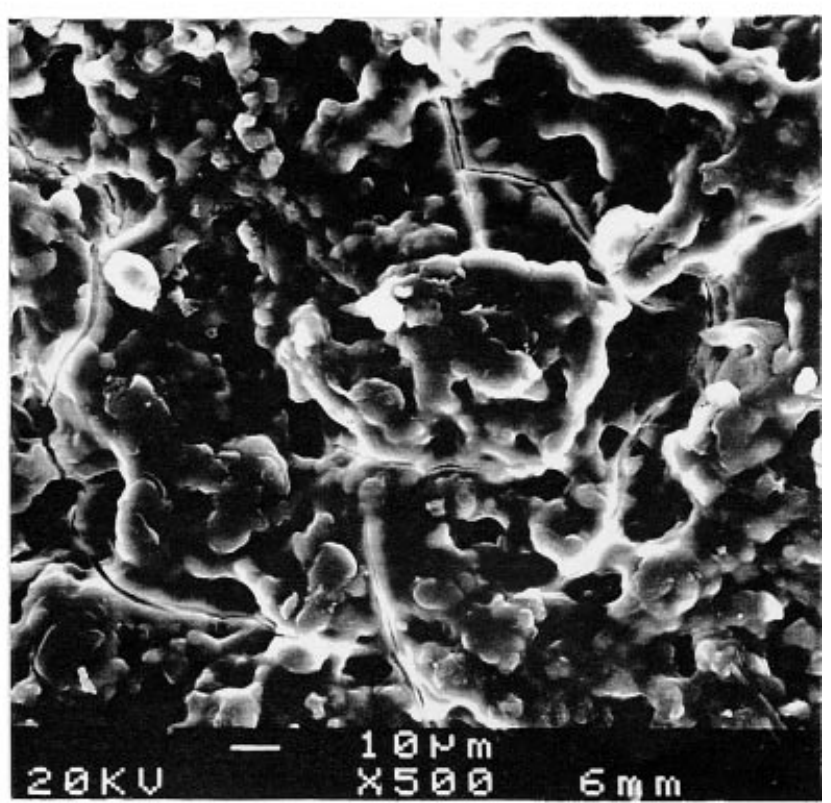

(d)

Figure 8. SEM photographs of surface of rice pasta made from GTJaponica rice flour, (a) without emulsifier addition and dried directly, (b) without emulsifier addition but steamed at $100^{\circ} \mathrm{C}$ for $1 \mathrm{~h}$ after extrusion, (c) with addition of $5 \mathrm{~g} \mathrm{~kg}^{-1} \mathrm{GMS}$ DIMODAN PM and dried directly, and (d) with addition of $5 \mathrm{~g} \mathrm{~kg}{ }^{-1} \mathrm{GMS}$ DIMODAN PM but steamed at $100^{\circ} \mathrm{C}$ for $1 \mathrm{~h}$ after extrusion.

$\left(5 \mathrm{~g} \mathrm{~kg}^{-1}\right)$ to the rice flour significantly improved the smoothness of the extrusion process. The texture of cooked rice pasta made from GTIndica (high-amylose) rice flour remained soft during serving when $10 \mathrm{~g} \mathrm{~kg}^{-1} \mathrm{GMS}$ was added. The rice pasta made with the addition of $10 \mathrm{~g} \mathrm{~kg}^{-1} \mathrm{KM} 3000$ provided cooked rice pasta with a chewable texture but yellow colour.

\section{ACKNOWLEDGEMENTS}

The author is grateful for financial support from Project 89AST-3.2-FAD-61(2)-3 of the Council of Agriculture Executive Yuan, Taiwan.

\section{REFERENCES}

1 Milatovic Lj and Mondelli G, Pasta Technology Today. Chiriotti Editori, Pinerolo, pp 1-24 (1991).

2 Matsuo RR, Durum wheat: its unique pasta-making properties, in Wheat: Production, Properties and Quality, Ed by Bushuk W and Rasper VF, Blackie Academic and Professional, Glasgow, pp 169-178 (1994).

3 Skerritt JH, Devery JM and Hill AS, Gluten intolerance: chemistry, celiac-toxicity, and detection of prolamins in foods. Cereal Foods World 35:638-644 (1990).

4 Rasanen L, Lehto M, Turjanmaa K, Savolainen T and Reunala $\mathrm{T}$, Allergy to ingested cereals in atopic children. Allergy (Copenhagen) 49:871-876 (1994).

5 Kasarda DD, The relationship of wheat proteins to celiac disease. Cereal Foods World 23:240-245 (1978). 
6 Kasarda DD and D'Ovidio R, Deduced amino acid sequence of an alpha-gliadin gene from spelt wheat (spelta) includes sequences active in celiac disease. Cereal Chem 76:548-551 (1999).

7 Silano M, Bioactive antinutritional peptides derived from cereal prolamins: a review. Nahrung 43:175-184 (1999).

8 Cruz FR, A study of the bijon industry in Bulacan and its vicinity. BS Thesis, University of the Philippines, Diliman, Quezon City (1959).

9 Resmini P, Lenner A, Debernardi G and Gerardo D, Technology and Ultrastructure of Pasta (Noodles) Produced with Rice Flour. Centro Ricerche Soc Braibanti, Milan (1979).

$10 \mathrm{Li} \mathrm{CF}$ and Luh BS, Rice snack foods, in Rice: Production and Utilization, Ed by Luh BS, AVI, Westport, CT, pp 690-711 (1980).

11 Juliano BO and Sakurai J, Miscellaneous rice products, in Rice Chemistry and Technology, Ed by Juliano BO, AACC, St Paul, MN, pp 569-618 (1985).

12 Tsao T, Beetner G, Lorenz K and Frey A, Extrusion processing of instant rice spaghetti. Lebensm Wiss Technol 9:96-98 (1976).

13 Umali JG, Physico-chemical properties of milled rice in relation to quality characteristics of noodles (bihon). MS Thesis, University of the Philippines, Los Banos, Laguna (1981).

14 Juliano BO and Pascual CG, Quality characteristics of milled rice grown in different countries. Int Rice Res Inst Res Paper Ser 48:25-31 (1980).

15 Stutz RL, Del Vecchio AJ and Tenney CJ, The role of emulsifiers and dough conditioners in foods. Food Prod Develop 7:52-56 (1973).

16 Eliasson AC, Starch gelatinization in the presence of emulsifiers. A morphological study of wheat starch. Starch 37:411-415 (1985).

17 Eliasson AC, Viscoelastic behavior during the gelatinization of starch. I. Comparison of wheat, maize, potato, and waxybarley starches. F Texture Stud 17:253-265 (1986).

18 Galloway GI, Biliaderis CG and Tanley DW, Properties and structure of amylose-glyceryl monostearate complexes formed in solution or on extrusion of wheat flour. F Food Sci 54:950 957 (1989).

19 AACC, Approved Methods of the American Association of Cereal Chemists, 9th edn. AACC, St Paul, MN USA (1995).
20 Juliano BO, Perez CM, Blakeney AB, Castillo T, Kongseree N, Laignelet B, Lapis ET, Murty VVS, Paule CM and Webb BO, International cooperative testing on the amylose content of milled rice. Starch 33:157-162 (1981).

21 Lai HM, Huang HL and Wu TP, Development of rice pasta products, in Achievements in Rice and Grain Products Processing, 1997. Eds Lin TC and Cheng YC, Council of Agriculture Executive Yuan, Taiwan, pp 60-82 (1998).

22 Stute R, Hydrothermal modification of starches: the difference between annealing and heat moisture treatment. Starch 44:205-214 (1992).

23 Hoover R and Vasanthan T, Effect of heat-moisture treatment on the structure and physicochemical properties of cereal, legume, and tuber starches. Carbohydr Res 252:33-53 (1994).

24 Jacobs H, Erlingen RC, Clauwaert W and Delcour JA, Influence of annealing on the pasting properties of starches from varying botanical sources. Cereal Chem 72:480-487 (1995).

25 Hoover $\mathrm{R}$ and Manuel $\mathrm{H}$, The effect of heat-moisture treatment on the structure and physicochemical properties of normal maize, waxy maize, dull waxy maize and amylomaize $\mathrm{V}$ starches. F Cereal Sci 23:153-162 (1996).

26 Lai HM, Effects of hydrothermal treatment on the physicochemical properties of pregelatinized rice flour. Food Chem 72:455-463 (2000).

27 Ghiasi K, Varrino-Marston E and Hoseney RC, Gelatinization of wheat starch. II. Starch-surfactant interaction. Cereal Chem 59:86-88 (1982).

$28 \mathrm{Krog} \mathrm{N}$, Influence of food emulsifiers on pasting temperature and viscosity of various starches. Starch 25:22-27 (1973).

29 Ryu GH and Walker CE, Emulsifier effects on pasting properties of wheat flour extrudates with/without sucrose and shortening. Starch 45:65-70 (1993).

$30 \mathrm{Xu}$ A, Chung OK and Ponte Jr JG, Bread crumb amylograph studies. I. Effects of storage time, shortening, flour lipids, and surfactants. Cereal Chem 69:495-501 (1992).

31 Ghiasi K, Varrino-Marston E and Hoseney RC, Gelatinization of wheat starch. I. Excess-water system. Cereal Chem 59:81-85 (1982).

32 Martin ML, Zeleznak KJ and Hoseney RC, A mechanism of bread firming. I: Role of starch swelling. Cereal Chem 68:498503 (1991). 